\title{
The History of Workforce Concerns in Pediatric Pulmonary Medicine
}

\author{
Christopher M. Oermann ${ }^{1}$, Thomas Lahiri ${ }^{2}$, Stacey Peterson-Carmichael ${ }^{3}$, and Pnina \\ Weiss $^{4}$ \\ ${ }^{1}$ University of Missouri Kansas City \\ ${ }^{2}$ University of Vermont College of Medicine \\ ${ }^{3}$ Wake Forest University \\ ${ }^{4}$ Yale University School of Medicine
}

August 11, 2020

\begin{abstract}
Children are affected by a broad spectrum of acute and chronic respiratory disorders. The number of children with respiratory disease is increasing, as are the complexity of disease pathophysiology and the management demands on pediatric pulmonologists. Despite slowing increasing numbers of board-certified pediatric pulmonologists, large areas of the country are underserved and there is a perception of an impending workforce crisis. There are multiple reasons for these concerns. A joint effort between the Pediatric Pulmonology Division Directors Association and Pediatric Pulmonary Training Directors Association was undertaken to address these issues.
\end{abstract}

\section{Introduction}

Pediatric lung disease is a significant cause of morbidity and mortality worldwide. A broad spectrum of lung diseases affects children from birth to adulthood. These include asthma, cystic fibrosis, neuromuscular disorders, chronic lung disease of prematurity, pulmonary hypertension, interstitial and diffuse lung diseases, sleep disorders, and others. The prevalence, morbidity, and mortality of these diseases vary widely. Asthma affects 10-15 percent of all children and has a significant negative impact on quality of life as well as other aspects of childhood health and wellbeing. Unfortunately, more than 210 children die of asthma each year in the United States. ${ }^{1}$ Cystic Fibrosis affects more than 30,000 individuals in the US, with $50 \%$ of them being children. Although life expectancy has significantly improved in recent decades (44.4 years in 2018), many children with CF die each year. ${ }^{2}$ The prevalence of other disorders is more difficult to quantify, but as a whole they contribute to substantial disease burden leading to poor health and wellbeing, decreased quality of life, and disease-related morbidity and mortality. The availability of Pediatric Pulmonologists to manage the long-term care of these children, conduct clinical research trials, and investigate the fundamentals of disease pathophysiology is crucial to addressing these issues.

\section{The History of Pediatric Pulmonary Medicine}

A rich history of interest in the pathophysiology of diseases affecting the respiratory systems of infants and children, as well as the tireless efforts of a small group of dedicated physician-scientists, led to the development of the American Board of Pediatrics (ABP) Pulmonology Sub-board in 1986. ${ }^{3,4}$ Since the inception of the sub-board, 1418 certificates have been issued by the ABP; among these 1151 remain active. ${ }^{5}$ The mean age of active certificate holders is 51.6 years, placing pediatric pulmonologists in the upper half of average age among all pediatric subspecialties. This statistic, coupled with the high proportion of unfilled fellowship 
positions and programs reported by the National Residency Match Program (NRMP), has led to significant concerns regarding the pediatric pulmonology workforce and future of the subspecialty. ${ }^{6}$

\section{Workforce Concerns}

Workforce issues have been a source of serious concern for the Pediatric Pulmonology Division Directors Association (PPDDA) and Pediatric Pulmonary Training Directors Association (PEPTDA) for the past two decades. Data from the American Board of Pediatrics indicate that the number of first year fellows in pediatric pulmonology has remained relatively static between 2001 and 2019. ${ }^{5}$ This is compared to significant increases in subspecialties such as Neonatal/Perinatal Medicine, Cardiology, Critical Care Medicine, Emergency Medicine, Endocrinology, Gastroenterology, and Hematology-Oncology (Figure 1). National Residency Match Program data demonstrate that there are significantly fewer pediatric pulmonology programs, fellowship positions, and fully matched programs compared to those subspecialties. ${ }^{7}$ During the 2020 match, there were only 52 applicants for 74 positions offered by 46 programs. Forty six percent of programs were unfilled, while $34 \%$ of positions were unfilled (Figure 2).

The reasons for this are complex and several scholarly articles have been written to address this concern. ${ }^{8-10}$ Potential contributing factors include: insufficient exposure to pediatric pulmonology in early years of medical education, subspecialty-specific factors, financial disincentives for fellows to complete training, and inadequate infrastructure to support physician-scientists and physician-educators. Attrition during training and an aging pediatric pulmonology workforce have also negatively impacted the availability of subspecialists. ${ }^{6,11}$ Some experts in the field have predicted the "extinction" of the physician-scientist in pediatric pulmonology. ${ }^{12,13}$

Of particular concern is that, despite the need to increase the pediatric pulmonology workforce, training programs are vulnerable to elimination because of inadequate funding streams. ${ }^{14,15}$ Graduate medical education funding by the Centers for Medicare and Medicaid Services and the Children's Hospital Graduate Medical Education Payment Program are unstable. The total number of institutional (T32) training grants sponsored by the National Institutes of Health has decreased over the last decade and potential federal budget cuts would further curtail the ability to train academic pulmonologists and physician scientists. ${ }^{14}$ Pediatric pulmonology training programs fit the profile of those at highest risk for being perceived by fellowship program directors as financially insecure, as they are primarily small ( 6 fellows or less), have $>25 \%$ unfilled positions and programs, and have a high proportion of funding from division or extramural sources. ${ }^{16}$ In fact, $27 \%$ of pediatric pulmonology program directors felt insecure about the future funding of their fellowships, which was higher than in other hospital-based subspecialties such as neonatal-perinatal medicine, critical care and emergency medicine. ${ }^{17}$

\section{PPDDA and PEPTDA Workforce Summit}

These issues potentially adversely impact the workforce which is already stretched such that significant portions of the United States are without adequate numbers of pediatric pulmonologists and children in those areas are underserved (Figure 3). A potential workforce crisis, in which the need for pediatric pulmonary medicine specialists exceeds supply, represents a serious threat to the respiratory health of children and may become a major public health crisis. For this reason, the combined memberships of the Pediatric Pulmonology Division Directors Association (PPDDA) and Pediatric Pulmonary Training Directors Association (PEPTDA) attempted to address these complex issues through a series of in-person meetings at the American Thoracic Society International Conference and North American Cystic Fibrosis Conference and ongoing conference calls. The larger group was divided into three work groups to address three separate areas of the pediatric pulmonology workforce issue: 1) factors impacting recruitment into pediatric pulmonology training programs, 2) evaluation of the effectiveness and outcomes of pediatric pulmonology training programs and 3) the pediatric pulmonary medicine landscape of the future. Each of these groups presents a summary of their work and recommendations to address the workforce issue in three additional installments.

\section{Acknowledgements}


The authors gratefully acknowledge the guidance and support of Eileen Larson and Rebecca Fisch (American Thoracic Society) for their many contributions to this effort. We also acknowledge, with appreciation, David Turner (American Board of Pediatrics) and Kehua Zhang (National Residency Match Program) for approval to reproduce figures.

\section{References}

1. CDC https://www.cdc.gov/asthma/asthmadata.htm

2. CFF Cystic Fibrosis Foundation Patient Registry. 2018 Annual Data Report. Bethesda, MD. (C)2019 Cystic Fibrosis Foundation.

3. Taussig, LM. History of the subboard in pediatric pulmonology. American Thoracic Society Historical Documents. 2007. https://www.thoracic.org/members/assemblies/assemblies/peds/resources/taussigv1.pdf.

4. Chernick V, Mellins RB. Pediatric pulmonology: a developmental history in north america. Pediatr Res. 2004 Mar;55(3):514-20.

5. American Board of Pediatrics, Pediatric Physicians Workforce Data Book, 2018-2019, Chapel Hill, NC: American Board of Pediatrics, 2019. https://www.abp.org/sites/abp/files/workforcedata2018-2019.pdf

6. Hayes D. Pediatric pulmonology workforce: an aging dilemma. Chest. 2014;146(3):e119-e120.

7. National Resident Matching Program, Results and Data: Specialties Matching Service 2020 Appointment Year. National Resident Matching Program, Washington, DC. 2020.

8. Macy ML, Leslie LK, Boyer D, Van KD, Freed GL. Timing and Stability of Fellowship Choices during Pediatric Residency: A Longitudinal Survey. J Pediatr. 2018 Jul;198:294-300.e1. doi:10.1016/j.jpeds.2018.03.034.

9. Gershan WM. Resident interest and factors involved in entering a pediatric pulmonary fellowship. BMC Med Educ. 2004;4:11. Published 2004 Jul 26. doi:10.1186/1472-6920-4-11

10. Rochlin JM, Simon HK. Does fellowship pay: what is the long-term financial impact of subspecialty training in pediatrics?. Pediatrics. 2011;127(2):254-260. doi:10.1542/peds.2010-1285

11. Hayes D, Kopp BT, Kirkby S, Allen ED, McCoy KS. Attrition in Pediatric Pulmonology Fellowship. Pediatric Allergy, Immunology, and Pulmonology. 2014;27(1):34-35.

12. Ferkol T, Zeitlin P, Abman S, Blaisdell CJ, O'Brodovich H. NHLBI training workshop report: The vanishing pediatric pulmonary investigator and recommendations for recovery. Pediatr Pulmonol. 2010;45(1):25-33.

13. Rubenstein RC, Kreindler JL. On preventing the extinction of the physician-scientist in pediatric pulmonology. Front Pediatr. 2014;2:4.

14. Workforce Committee. Financing Graduate Medical Education to Meet the Needs of Children and the Future Pediatrician Workforce. Pediatrics. 2016;137(4).

15. Chandra A, Khullar D, Wilensky GR. The Economics of Graduate Medical Education. New England Journal of Medicine. 2014;370(25): 2357-2360.

16. Weiss P, Myers AL, McGann KA, Mason KE, Kesselheim JC, Fleming GM, Barron C, Klasner A, Heyman MB, Weiss DL, Mauer E, Gerber LM, Abramson EL. Funding Sources and Perceived Financial Insecurity in Pediatric Fellowship Programs. Academic Pediatrics 2019;19(4).

17. Weiss, P., E. Mauer, D. Boyer, E.L. Abramson. Funding Sources and Effects of Limited Funding in Pediatric Pulmonology Fellowship Programs. Pediatric Pulmonology 55(1): 221-225, 2020.

Figure 1

ABP data representing trends in the number of individuals starting the first year of fellowship training in 14 pediatric subspecialties. Reproduced with the permission of the ABP. 


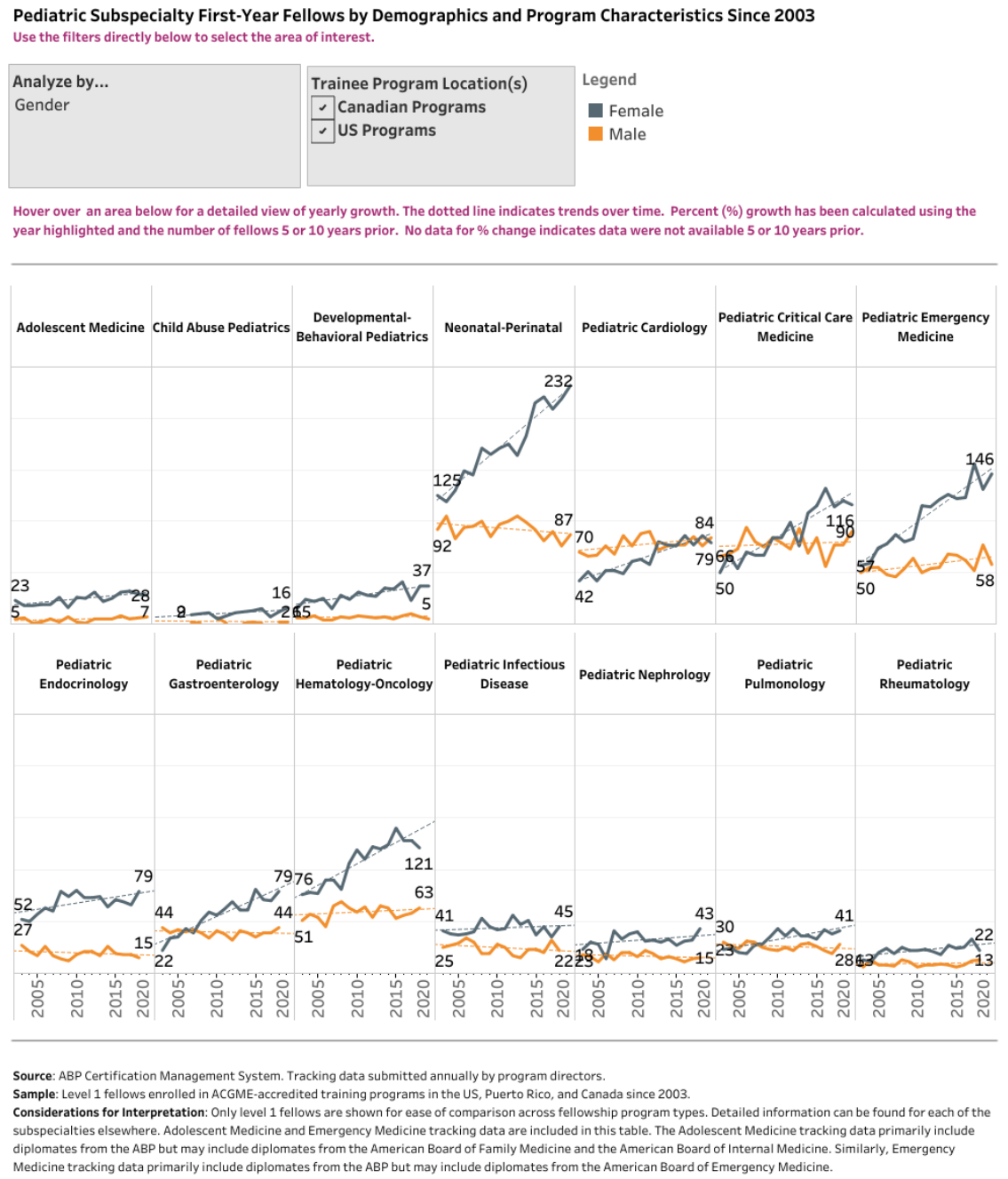

\section{Figure 2}

NRMP data regarding pediatric pulmonology program and position filling, and applicant match success. Reproduced with the permission of the NRMP.

\section{Hosted file}

image2.emf available at https://authorea.com/users/350257/articles/475121-the-history-ofworkforce-concerns-in-pediatric-pulmonary-medicine

\section{Figure 3}

ABP certified pediatric pulmonologists per 100,000 children by state. Reproduced with the permission of the ABP. 
2019 Distribution of US-Based Pediatric Subspecialists Ever Certified by the ABP, Age 70 and Under

- Use the filter directly below to select between pediatric subspecialties.

- Hover over

\begin{tabular}{|l|c|c|}
\hline $\begin{array}{l}\text { Subspecialty Certification } \\
\text { Pediatric Pulmonology }\end{array}$ & US-Based Pediatricians Ever Certified in \\
& Pediatric Pulmonology & Average Per State \\
\hline & $\mathbf{1 , 1 9 4}$ & $\mathbf{2 3 . 0}$ \\
\hline
\end{tabular}

Pediatricians Certified in Pediatric Pulmonology per 100,000 Children

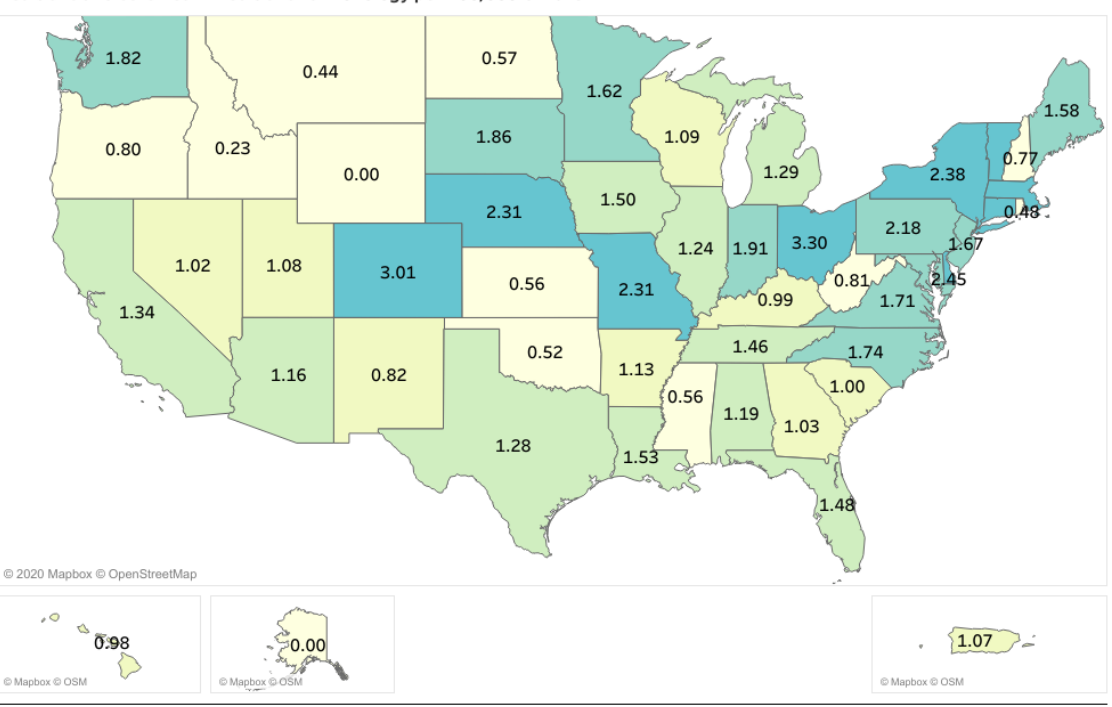

Ranking per 100,000 Children

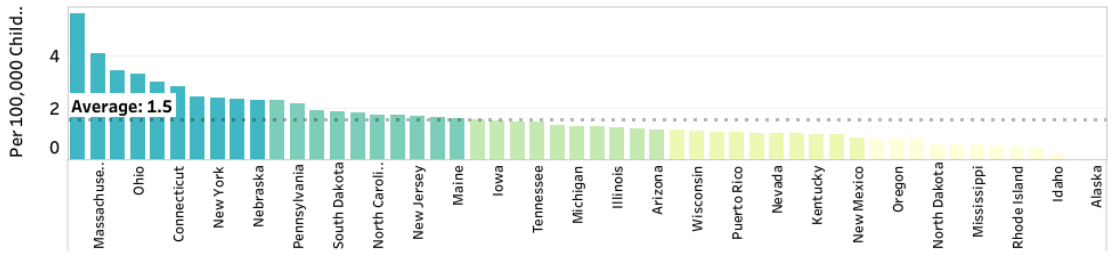

Color Coding: Colors displayed by state rank of pediatricians to 100,000 children, from highest (darkest) to lowest (lightest).

Contion Management System (January 2019) and the US Census Bureau Population Estimates from 2017.

Sample: Since 2016, US-based diplomates ever certified, age $\underline{70}$ and under. Child population estimates include Children age 17 and under.

adng dat consideratiorie sy subpretation:

this analysis views those starting with a General Pediatrics certification. Slight variations from other dashboards or reports regarding the numbers by state or total are de

to age differences or address changes found when obtaining data from two different time periods (January vs. July).

This analysis may miss physicians not certified in general pediatrics by the ABP, but certified solely by other ABMS member boards for some subspecialties (ie, Adolescent Medicine and Pediatric Emergency Medicine). This dashboard excludes certifications granted at other ABMS member boards due to possible address inaccuracies (ie, Hospice and Palliative Care, Medical Toxicology, Neurodevelopmental Disabilities, Sleep Medicine, Sports Medicine, and Transplant Hepatology). Pediatricians may become certified in one or more areas and are represented for each of their respective subspecialties here. Information is not available concerning how many pediatric diplomates are in clinical practice, are working part-time/full-time, and are deceased. 
Pediatric Subspecialty First-Year Fellows by Demographics and Program Characteristics Since 2003 Use the filters directly below to select the area of interest.

\begin{tabular}{|c|c|}
\hline $\begin{array}{l}\text { Analyze by... } \\
\text { Gender }\end{array}$ & $\begin{array}{l}\text { Trainee Program Location(s) } \\
\begin{array}{|ll}\text { Canadian Programs } \\
& \text { US Programs } \\
\end{array}\end{array}$ \\
\hline
\end{tabular}

Hover over an area below for a detailed view of yearly growth. The dotted line indicates trends over time. Percent $(\%)$ growth has been calculated using the year highlighted and the number of fellows 5 or 10 years prior. No data for $\%$ change indicates data were not available 5 or 10 years prior.

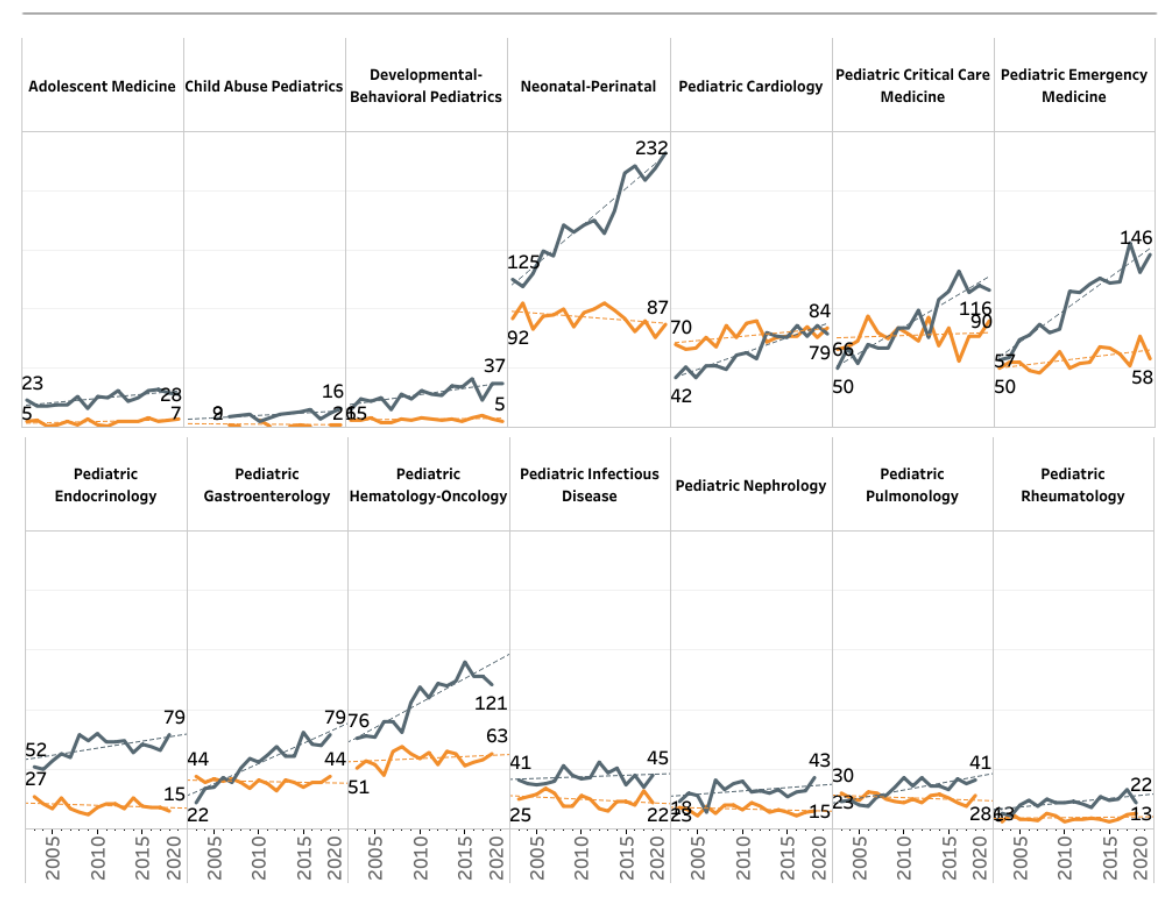

Source: ABP Certification Management System. Tracking data submitted annually by program directors. Sample: Level 1 fellows enrolled in ACGME-accredited training programs in the US, Puerto Rico, and Canada since 2003.

Considerations for interpretation: Only level 1 fellows are shown for ease of comparison across fellowship program types. Detailed information can be found for each of the subspecialties elsewhere. Adolescent Medicine and Emergency Medicine tracking data are included in this table. The Adolescent Medicine tracking data primarily includ diplomates from the ABP but may include diplomates from the American Board of Family Medicine and the American Board of Internal Medicine. Similarly, Emergency Medicine tracking data primarily include diplomates from the ABP but may include diplomates from the American Board of Emergency Medicine. 
Fellowship Match Trends by Specialty and Appointment Year

Pediatric Pulmonology

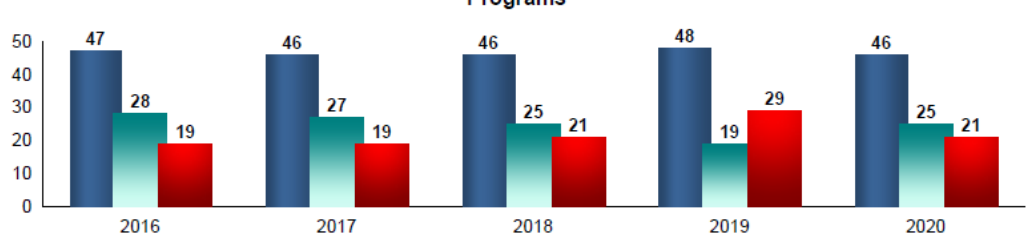

- Number of Programs - Programs Filled - Programs Unfilled

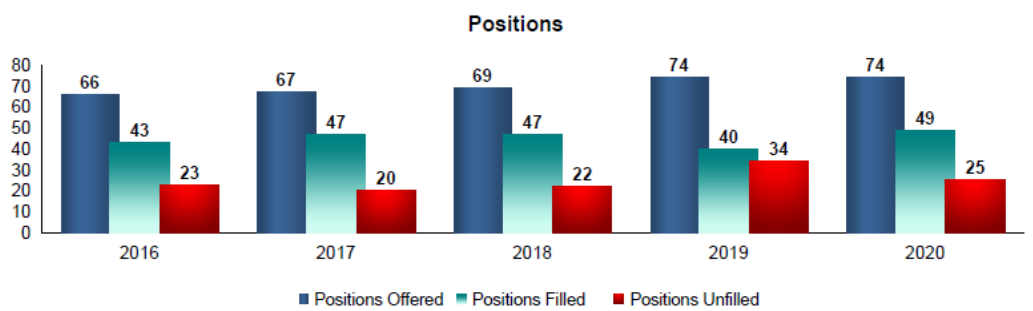

- Positions Offered = Positions Filled a Positions Unfilled

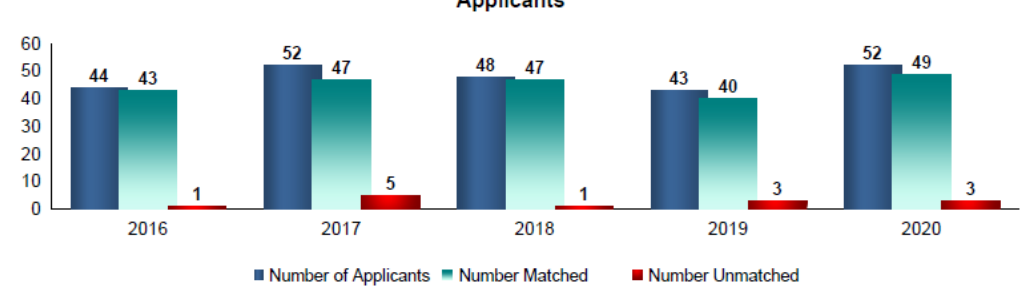

Number of Applicants Per Position and Percent of Applicants Matched

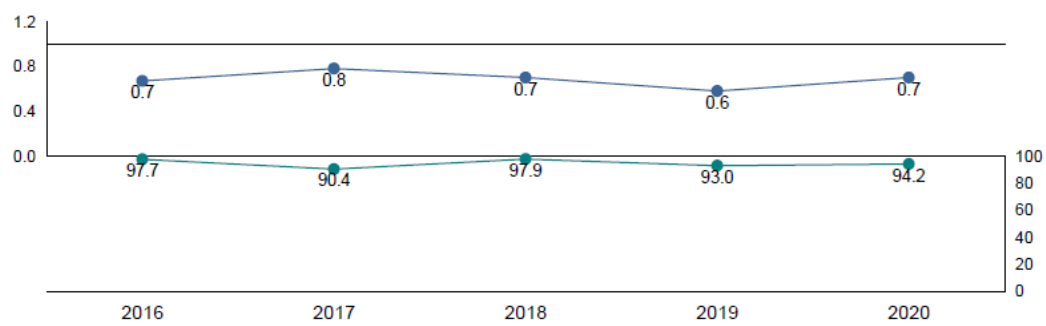


2019 Distribution of US-Based Pediatric Subspecialists Ever Certified by the ABP, Age 70 and Under

Use the filter directly below to select between pediatric subspecialties.

Hover over or click a state for more information. Use the map tools in the upper left of the map to select more than one state or to move the map. Click outside the area to return to the full map display.

Subspecialty Certification

Pediatric Pulmonology

US-Based Pediatricians Ever Certified in

Pediatric Pulmonology

Average Per State

23.0

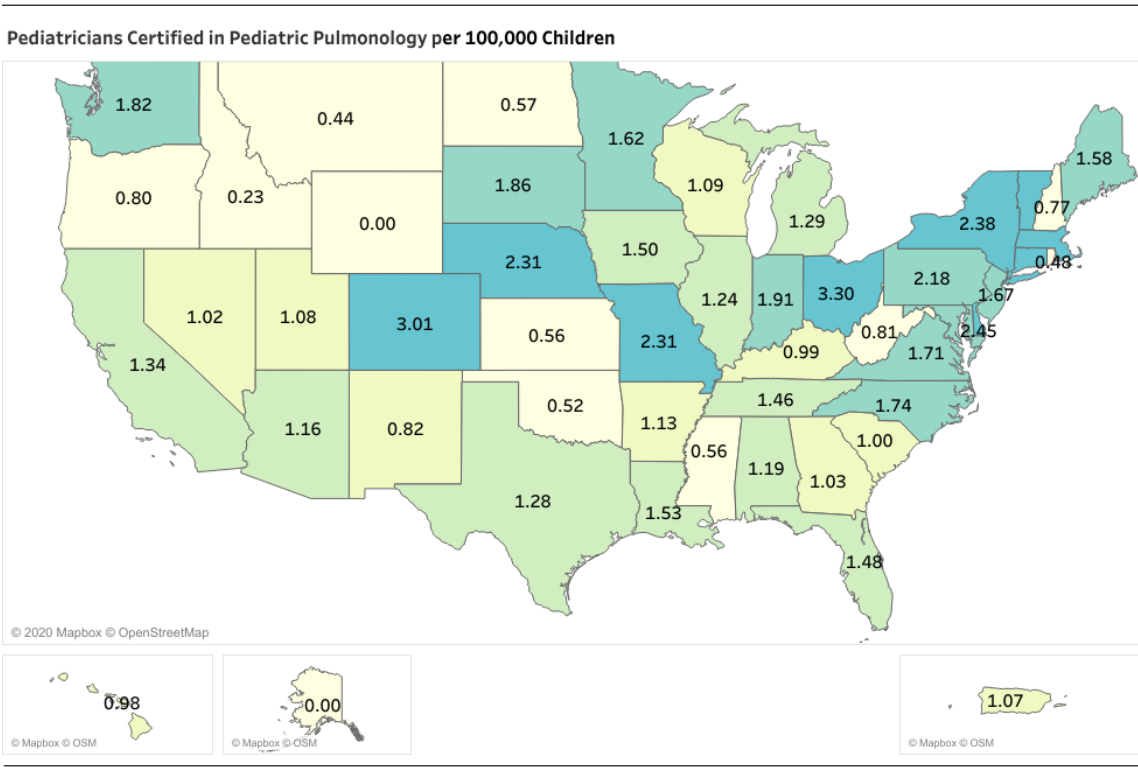

Ranking per 100,000 Children

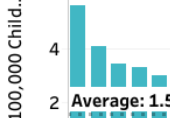

ఏ 0

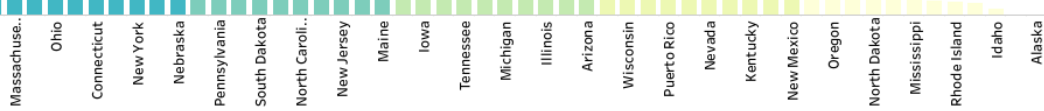

Color Coding: Colors displayed by state rank of pediatricians to 100,000 children, from highest (darkest) to lowest (lightest).

Source: ABP Certification Management System (January 2019) and the US Census Bureau Population Estimates from 2017.

Sample: Since 2016, US-based diplomates ever certified, age $\underline{70}$ and under. Child population estimates include children age 17 and under.

Missing data/considerations for interpretation: Caution should be used when interpreting the estimates provided. State location is determined using the latest mailing address on file. Count varies by subspecialties chosen. All ABP pediatricians must be certified in General Pediatrics before becoming certified in a subspecialty, therefore, this analysis views those starting with a General Pediatrics certification. Slight variations from other dashboards or reports regarding the numbers by state or total are due to age differences or address changes found when obtaining data from two different time periods (January vs. July).

This analysis may miss physicians not certified in general pediatrics by the ABP, but certified solely by other ABMS member boards for some subspecialties (ie, Adolescent Medicine and Pediatric Emergency Medicine). This dashboard excludes certifications granted at other ABMS member boards due to possible address inaccuracies (ie, Hospice and Palliative Care, Medical Toxicology, Neurodevelopmental Disabilities, Sleep Medicine, Sports Medicine, and Transplant Hepatology). Pediatricians may become certified in one or more areas and are represented for each of their respective subspecialties here. Information is not available concerning how many pediatric diplomates 